\title{
CRANIOFACIAL, ORAL AND DENTAL MANIFESTATIONS OF ORAL BREATHING
}

\section{MANIFESTAÇÕES ORAIS, DENTÁRIAS E CRANIOFACIAIS DA RESPIRAÇÃO BUCAL}

Omar Franklin Molina', Angra Silva Mendes², Isabella Rodrigues da Silveira ${ }^{3}$, Karin Ferretto Collier ${ }^{4}$, Zeila Coelho Santos ${ }^{5}$, Vanessa Bastos Penoni ${ }^{6}$, Karla Regina Gama ${ }^{7}$.

\section{RESUMO}

Introdução: A respiração bucal é um distúrbio respiratório patológico que afeta muitas estruturas orais, dentais e craniofaciais.

Objetivo: Avaliar as manifestações clinicas da respiração bucal e explorar os mecanismos que provocam alterações dentárias, craniofaciais e orais em crianças.

Metodologia: As palavras chaves ou termos respiração bucal e frequência, respiração bucal e etiologia, respiração bucal e sinais e sintomas, respiração bucal e mecanismos, respiração bucal e diagnóstico e respiração bucal e tratamento foram usadas na procura de artigos científicos no Google Schoolar.

Resultados e discussão: A pesquisa obteve 25 artigos científicos escritos em inglês no período 2000-2016 e 4 artigos publicados na mesma língua e no período1981-1997. Os artigos mencionados tinham material escrito o suficiente para explorar os diversos aspectos da respiração bucal.

Considerações finais: As manifestações clínicas da respiração bucal relacionada com alterações craniofaciais em crianças e adolescentes incluem alterações dentárias, posturais, anormalidades musculares-esqueléticas, anatômicas, oclusais, orais e neuromusculares. Os mecanismos da respiração bucal que provocam distúrbios patológicos incluem fatores obstrutivos, posturais, diminuição do efeito vertical dos músculos sobre os dentes posteriores, posicionamento lingual anterior, alteração das forças musculares exercidas pela língua, aumento do gasto de energia, uma cavidade bucal menor, maxila e mandíbula retruídas, e resistência aumentada do nariz na passagem do ar.

Descritores: Respiração bucal. Manifestações clínicas. Patofisiologia. Mecanismos. Sinais e sintomas.

\section{ABSTRACT}

Introdução: Mouth breathing is a pathological respiratory pathological disorder affecting many oral, dental and craniofacial structures.

Objectives: Evaluate the clinical manifestations of mouth breathing and explore the mechanisms causing oral breathing, craniofacial, oral and dental alterations in children.

Methodology: Using the key words mouth breathing, frequency; mouth breathing etiology; mouth breathing signs and symptoms, mouth breathing pathophysiology; mouth breathing signs and symptoms, mouth breathing diagnosis and mouth breathing treatment, we entered these key words in the Google Schollar.

Results and discussion: We retrieved 25 papers written in English in the period 200-2016 and four papers written in the same language and published in the period 1981-1997. All these papers had sufficient oral breathing associated content in order to prepare the current study.

Final considerations: Clinical manifestations of mouth breathing associated with craniofacial alterations in children include dental changes, craniofacial alterations, postural abnormalities, musculoskeletal disorders, anatomical alterations, occlusal, oral and neuromuscular disorders. Mechanisms of mouth breathing causing pathological disorders in children include obstructive, postural, reduction of vertical effect on muscles, anterior tongue thrusting anatomical, disruption of muscle forces exerted by the tongue, increased expenditure of energy during sleep, smaller oral cavity, retruded maxilla and mandible and increased nasal airway resistance.

Descriptors: Mouth breathing. Clinical manifestations. Pathophysiology. Mechanisms. Signs and Symptoms.
' Dentistry. Lecturer at the Dentistry Course of UnirG University Center.

Postdoctoral degree from Harvard University, USA. Master in Pediatric Dentistry Federal University of Santa Catarina, UFSC.

E-mail: omar-nyorkerharvardtexas@hotmail.com

MAILING ADDRESS: Dentistry Clinic of UnirG University Center, Pará Avenue, 1544 - St. Central, Gurupi - TO, 77403-010, Phone: (63) 3612-7579.

\section{INTRODUCTION}

Respiration is one of the body's vital functions and under physiological conditions, breathing takes place in the nose. The mouth breathing syndrome (MBS) is when a child has mixed breathing i.e., nose breathing is supplemented by the mouth ${ }^{1}$. Breathing is a vital function and is strongly dependent on the adequate permeability of the nasal route, establishing itself as the main function of the body.

The nasal cavity has a fundamental role in the physiology of respiration as it promotes filtering, heating and humidification of the inhaled air $^{2}$. Nasal breathing is the primary mode of air intake for humans, and is essential for a supply of properly cleansed, moistened and warmed air for the lungs. If the primary airway is blocked, mouth breathing 
becomes the only airway available to get air into the lungs ${ }^{3}$. Nasal breathing is the correct mode of breathing in order to attain correct growth and development of the craniofacial complex ${ }^{4}$. Because of nasal airway inadequacy or habit, in some individuals the oral cavity becomes the established and predominant route for the passage of respiratory airflow.

According to the Moss theory ${ }^{5}$ or theory of the functional matrix, only nasal breathing allows proper growth of the dentofacial complex. Moss theory is based on the principle that normal nasal respiratory activity influences the development of craniofacial structures, favoring a balanced growth pattern by adequately interacting with chewing and swallowing ${ }^{6}$.

The association between respiratory disorders and oral, craniofacial and dental disorders has been investigated using a number of approaches. There is a potential or actual interaction between respiratory function and craniofacial growth pattern ${ }^{7}$. Mouth breathing usually occurs as a vicious habit out of the need to adapt due to partial nasopharyngeal obstructions $^{8}$. Mouth breathing brings adverse effects on one's oral health ${ }^{9}$.

Because it is not known to what extent nasal resistance or mouth breathing influences dental and craniofacial complex, and the relevance of airway obstruction and mechanisms implicated in alterations in facial growth and development, have not been fully determined, this study was designed to: 1 - Evaluate the clinical manifestations of mouth breathing in children; 2 - Assess the mechanisms causing oral breathing, craniofacial, oral and dental alterations in children.

\section{METHODOLOGY}

We used the Key Words Mouth breathing etiology; Mouth breathing pathophysiology; Mouth breathing frequency; Mouth breathing diagnosis and Mouth Breathing Treatment to collect papers in order to prepare this study.

Inclusion criteria: Only papers written in English, papers with clinical cases, case reports and published between 1999 and 2016 were accepted to carry out the current investigation.

Different key words were used to collect papers in order to discuss different subjects in the literature review. The electronic site scholar.google.com was the only one from which all scientific papers were retrieved. Exclusion criteria were the following: Papers published before 1999, papers written in Portuguese, Spanish, French and other languages and papers with insufficient content to discuss different subjects in the review of the literature.

\section{DEVELOPMENT}

\section{Mouth Breathing}

Mouth breathing is a respiratory disorder that affect children, adolescents and even adults in a large percentage of the general population and is responsible for local and systemic pathological effects in the short and long-term.

Many domains of the general health of a child, adolescent and adult may be affected when mouth breathing is present. Mouth breathing syndrome is defined as a set of signs and symptoms that may be completely or incompletely present in subjects who, for several reasons replace the correct pattern of nose breathing by an oral or mixed pattern present for more than six months ${ }^{2}$. The mouth - breathing syndrome is when a child has mixed breathing i.e., during breathing the function of the nose is supplemented by the function of the mouth ${ }^{1}$.

\section{Frequency}

Mouth breathing is a respiratory dysfunction that affects approximately $10-15 \%$ of child population ${ }^{10}$. Mouth breathing has a frequency of $14 \%$ among children with dental and maxillary abnormalities, girls (55.8\%) being more affected than boys and occurs very frequently in children living in urban areas $(79 \%)^{11}$. In children, mouth breathing was found to be the second most common oral habit after tongue thrust ${ }^{12}$.

One investigation ${ }^{11}$, evaluated a sample of 307 children and adolescents aged 5-16 years and reported an incidence of $40.2 \%$ mouth breathing. The frequency of this disorder was almost equally distributed in girls and boys. When researchers ${ }^{11}$ analyzed the frequency of mouth breathing by age, they reported a higher frequency $(62.8 \%)$ in $10-12$ years-old children as compared to children and adolescents in other age groups.

\section{Etiology}

The most common cause of nasal obstruction in children is hypertrophy of the adenoids, which is the nasopharyngeal pad of lymphoid tissue. Children and adolescents usually present the so called "Adenoid Facies". The features of "adenoid facies" are listed below: 1.Pinched nostrils, short upper lip; 2.Open mouth posture and elongated face; 3.Increased lower, steep angle of mandible; 4.Mandibularretrognathism, vacant expression; 5.Prominent upper teeth, narrow upper alveolus, hypoplastic maxilla, anterior tongue position, retroclined mandibular incisors ${ }^{13}$.

It has been established that enlarged adenoids are mainly responsible for obstructive mouth breathing. However, some children continue 
to breaththrough their mouth even after surgical removal of their adenoids. This could be due to habitual mouth breathiness and laziness in using the nose despite having an adequate nasal airway ${ }^{3}$. It may be that in many children there are some mechanical obstacles other than adenoids preventing the child from nasal breathing ${ }^{3}$. In fact, it seems that a combination of upper airway and nose anatomic disorders are more likely to cause a shift from nose to mouth breathing. Mechanical barriers that may contribute to the blockage of the nasal air passage and cause the child to shift to a pattern of mouth breathing include anatomical variations present in the nasal cavity and the paranasal region during development in the turbinate and concha bullosa regions, as well as inflammatory sinus and nasal changes such as recurrent chronic sinusitis and hypertrophy of the inferior nasal concha ${ }^{3}$.

One study ${ }^{3}$ evaluated a sample of 67 children with ages ranging from 10 to 15 years. They were grouped in those with and without mouth breathing. In mouth breathers researchers reported a frequency of $87 \%$ hypertrophied adenoids, $77 \%$ of maxillary sinusitis, $55 \%$ had a deviated nasal septum, $55 \%$ had hypertrophied inferior concha, $45 \%$ had ethmoid sinusitis and $23 \%$ showed frontal sinusitis. Such changes were significantly less prevalent in non mouth breather children. Mouth breathing is often associated with obstruction or congestion of the upper respiratory tract ${ }^{3}$.

Regarding factors associated with upper airway obstruction, they include developmental disorders, macroglossia, anatomical constriction of airway, enlarged tonsils/adenoids, nasal polyps, and allergic rhinitis, but enlarged adenoids and tonsils are consideredas major contributing factors ${ }^{14}$.

In one investigation ${ }^{3}$, mouth breathing children showed a significantly higher incidence of septal deviation as compared with nose breathing children.It was found that the overall incidence of sinusitis was generally higher in mouth breathers than in nose breathers.

One study ${ }^{3}$ evaluated the frequency and etiology of mouth breathing in children and reported a frequency of inflammatory changes and adenoid hypertrophy in $87.1 \%$ in mouth breathers as compared to only $31 \%$ in non mouth breathers. The higher frequency of adenoid hypertrophy emphasizes the leading role of adenoid as etiologic factor in mouth breathing ${ }^{3}$.Cuc and $\mathrm{Cuc}^{11}$, evaluated a sample of 307 children aged $5-16$ years and reported a frequency of $43 / 307=14 \%$ of mouth breathing. The most common causes of this disorder were habitual mouth breathing $(12 \%)$, enlarged adenoids (60\%) and deviated septum (28\%). It has been reported that the nasopharyngeal air space is markedly reduced in mouth breathing children and in apneic patients ${ }^{15}$.

\section{Pathophysiology or mechanisms in mouth breathing}

Decreased incidence of competent upper lip in mouth breathing children is attributed to high nasal resistance, hence, an open mouth posture allows for adequate air intake through the mouth ${ }^{3}$. It may be that because the muscles around the nose are not physiologically used, some atrophy also occurs in the upper lip, thus leading to hypotony. Sinusitis is a common finding in mouth breathing children, adolescents and adults.

The reasons for a higher incidence of sinusitis in mouth breathing children can be explained as follows: Inflammatory sinus disease offers a mechanical obstacle against the airflow through the nasal passage. Additionally, sinusitis is usually associated with blockage of the osteomeatal unit, which poses a second barrier facing the airflow. It has been established by the newly developed unified airway concept that the respiratory system functions as an integrated unit and that diffuse inflammation often affects the mucosal surfaces of the nose, sinuses, middle ear and tracheobronchial tree simultaneously ${ }^{3}$.

Mouth breathing usually develops as a consequence of nasal resistance ${ }^{4}$. In one study ${ }^{16}$, nasal obstruction was induced in experimental animals. Obstruction resulted in mouth breathing, maxillary narrowing, increased lower facial height, malocclusion and dental anomalies. Retruded maxilla and mandible in patients with oral breathing and obstructive sleep apneia, leads to a smaller oral cavity, diminished functional space for the tongue, which will occupy a more posterior position, thus favoring, obstruction of the upper airway during sleep $^{15}$. Lymphoid tissue hypertrophy plays an important role in the pathophysiology of both oral breathing and sleep apneia in children. Maintaining nose breathing during childhoodis important for preventing abnormalities of the facial skeleton ${ }^{15}$.

Habitual mouth breathing is often accompanied by habitual anterior tongue posture, instead of alip closure, in order to create the anterior seal necessary for the initiation of physiological deglutition ${ }^{17}$. Anterior tongue thrusting during swallowing exerts pressure forces on teeth that typically counteract the orthodontic forces that are applied for a closure of an open bite ${ }^{17}$. Anterior forward head posture in mouth breathing children and adolescents acts with the purpose of facilitating air entry through the mouth, resulting in postural changes that determine the worsening of pulmonary function creating a feedback mechanism that generates progressive respiratory and musculoskeletal disorders ${ }^{2}$.

Postural changes areone mechanism that is related with the clinical manifestations of mouth breathing. In one experimental stud in monkeys ${ }^{18}$, 
the nasal openings were closed with latex plugs so as to inhibit nose breathing. The sudden change from nasal to oral respiration caused severe alterations in the function of the chewing muscles. The ultimate facial and dental abnormalities depended on three forms of respiration adopted by animals. Some monkeys that rhythmically lowered and raised their mandibles in each breath developed a class I open bite; animals that rotated their mandibles in a posterior and inferior direction developed a class II malocclusion, and animals that maintained their mandibles in an anterior position developed a class III malocclusion and a skeletal class III profile ${ }^{18}$.

\section{Signs and symptoms}

Sign and symptoms of oral breathing include a long face, dark circles around the eyes, postural position with open mouth, flattened cheek bones, short and incompetent upper lip, small and hypotonic nostrils, low-lingual posture, a posterior rotation of the mandible, a tendency to open bite, hyperextension and rotation of the head, extrusion of the posterior teeth, posterior cross-bite, constricted maxilla, lingual positioning of posterior upper teeth and arched palate ${ }^{10}$. Additional signs and symptoms in mouth breathing children and adolescents include daytime sleepiness, headache, agitation and nocturnal enuresis, frequent fatigue, poor appetite, bruxism, school problems, learning deficits and behavioral disorders, irritability during the day, snoring, sleeping with mouth open, restless sleep, nasal obstruction ${ }^{2}$.

Other signs and symptoms include lack of lip seal, V-shape and/or arched palate, class II malocclusion, unilateral or bilateral cross-bite, open bite, sleep apnea, facial rotation of the lower lip, retracted upper lip, generalized facial hypotonia, postural changes, dark circles, elongated face, lowered mandible, dental alterations, abnormal speech, abnormal tongue position and mentual muscle hyperfunction during lip-closure ${ }^{2}$. Attention deficit hyperactivity disorder or ADHD is commonly found among mouth breathing children. It is known that both mouth breathing and ADHD may trigger sleep disorder breathing. Both ADHD and mouth breathing can trigger sleep disorder breathing ${ }^{19}$.

\section{Oral and dental manifestations}

Mouth breathing causes malocclusion, abnormal dental alignment, dryness of the oral tissues, compromising gingival health and leading to dental caries and oral malodour ${ }^{3}$. Mouth breathing is often associated with the long face syndrome and adenoid facies. Patient with this syndrome usually present increased facial height, lip apart posture, narrow alar base and frequently self reported mouth breathing $^{20}$. Intraorally, there is usually a narrow maxillary arch, a high palatal vault, a shorter left and right molars distance, a posterior cross bite and a class II dental maloclussion ${ }^{20}$.

One investigation ${ }^{5}$, evaluated children presenting with mouth breathing that were compared with a control group of non mouth breathing children. Researchers reported that $11 / 44=25 \%$ of the mouth breathing group presented with a unilateral posterior cross-bite and $5 / 44=11.4 \%$ with a bilateral posterior cross bite. Mouth breathing children also presented a smaller palatal surface and volume as compared to the control group. Mouth breathing in children leads to hypotrophy of the maxillary complex, resulting in narrowing of both intermolar and intercanine widths ${ }^{5}$.It has been reported ${ }^{19}$ that mouth breathing is associated with snoring at night, waking up during the night, dry mouth and sleepiness during the day. The most commonly described speech disorders in mouth breathers include anterior position of the tongue during production of lingual dental phonemes, inaccuracy of bilabial phonemes in Portuguese and frontal/lateral lips ${ }^{21}$.

\section{Craniofacial manifestations}

Using mouth breathing on a regular basis,can cause many serious problems, mainly inadequate facial growth and bone development ${ }^{3}$. One clinical investigation ${ }^{7}$ reviewed some aspects of growth pattern in children and reported that there is an association between mouth breathing patterns, increased lower anterior facial height and deep antigonial notches. A mandibular antigonial notch is associated with the mandibular growth direction. One investigation ${ }^{7}$ assessed an association between breathing pattern and mandibular morphology and reported that deep mandibular antigonial notch and vertically directed growth pattern were more prominent in mouth breathers than in non mouth breathers ${ }^{7}$.

There is sufficient information indicating that mouth breathing reduces anterior maxillomandibular development, such that these structures are more retrudedin relation to the skull base ${ }^{15}$. Among the consequences of mouth breathing are alterations of craniofacial growth, abnormal body posture, abnormal muscle tone, flaccid jaw elevator muscles, anterior head posture and maxillary atresia ${ }^{20}$. The amount of dentoalveolar and skeletal deformation in mouth breathers is related to the frequency, duration, direction and intensity of certain habits and should be assessed by the dentist and physician. Changes that may occur to the dentoalveolarstructures include anterior or posterior open bite, interference of normal tooth position and eruption, alteration of bone growth and development and cross bites ${ }^{22}$. 


\section{Diagnosis}

To identify enlarged adenoids, a lateral cephalometric radiograph of the nasopharynx provides a valuable method in the evaluation of children with upper airway obstruction for assessing adenoid size. We emphasize that a cephalometric radiograph only shows a bidimensional anatomy of a structure which is tridimensional anatomically speaking. Thus, CBTC may be required to assess volume and proper anatomy of enlarged adenoids ${ }^{13}$. Early diagnosis in collaboration with the pediatrician is mandatory in order to design proper interceptive treatment. Early diagnosis is the first step in the diagnosis and treatment dyad. In this way, is possible to prevent several conditions including frequent infections, a pathological chewing pattern, the development of a malocclusion, incorrect swallowing, inadequate speech and body posture abnormalities ${ }^{10}$.

\section{Treatment}

Treatment of enlarged adenoid tissue includes a course of antibiotic (Clindamycin or augmentin) which acts again beta-lactamase producing pathologic organisms. Surgical intervention includesadenoidectomy with or without tonsillectomy, conservative septal surgery in growing patients, and radiofrequency inferior turbinate reduction which is performed with a specially designed probe with a needle at the end, placed into the submucosalstroma of the inferior turbinate and controlled radiofrequency energy is delivered for tissue ablation ${ }^{13}$. One follow up investigation $^{23}$ evaluated facial growth in children with severe nasopharyngeal obstruction and mouth breathing. Researchers compared the treatment using adenoidectomy and the outcome was compared with the growth direction in normal control children. Researchers reported that the sample treated with adenoidectomy initially showed lower face heights and five years following surgery, children showed a more horizontal lower jaw growth direction, but this difference was significant only for girls.

Orthodontic treatment includes maxillary expansion using a quad-helix appliance or a rapid maxillary expansion with a hyrax screw or palatal distractor. Mandibular advance devices may also be used to enlarge the upper airway ${ }^{13}$. In one review of the literature ${ }^{3}$, researchers found that upper airway relief, most commonly, by performing adenoidectomy, can lead to a normalization of occlusion in children who were obligate mouth breathers. Regarding treatment of a class II malocclusion, posterior cross bite and a narrow maxillary arch together with mouth breathing, a combination of orthodontics and surgery may be recommended in non growing patients. Studies ${ }^{20}$ have demonstrated that this treatment leads to balanced vertical height proportions, improved lip contact at rest and improved facial aesthetics. It has been suggested that when evaluation and proper diagnosis is carried out at an earlier age including diagnosis of nasal obstruction, appropriate orthodontic intervention using maxillary expansion may resolve the vertical facial growth pattern at an earlier age with the advantages of improving aesthetic, function, facial morphology and perioral muscle function ${ }^{20}$.

Surgically assisted maxillary expansion may be carried out in adults presenting with severe malocclusion and is considered a relatively safe technique. Planned bilateral sagittal split surgery advances the mandible, widens the airway and relieves the symptoms of upper airway obstruction ${ }^{13}$. A mandibular advancement splint is a very useful technique in elder patients who have sleep apnea due to narrowing of the pharyngeal airway space. This device is thought to place the mandible in an anterior position thus, increasing pharyngeal airway space enabling the passage of increased air volume.

Maxillary expansion improves nasal volume and flow and alleviates the symptoms of upper airway obstruction ${ }^{13}$. One clinical investigation ${ }^{24}$ tested the efficacy of speech therapy to achieve nasal breathing awareness and automation in conjunction with intranasal beclomethasone dipropionate in children presenting with mouth breathing, asthma and allergic rhinitis.

Researchers reported that speech therapy and beclomethasone improved significantly respiratory capacity as compared to the use of medication alone. Speech therapy and eclo methasone dipropionato had a positive impact on functional and clinical management of both asthma and allergic rhinitis in mouth breathing children.

\section{RESULTS AND DISCUSSION}

\section{Etiology of mouth breathing}

Hypertrophy of the adenoids and palatine tonsils is the second most common cause of upper respiratory obstruction and consequently, of mouth breathing in children ${ }^{25}$. One investigation ${ }^{26}$ asserts that the etiology of mouth breathing is multifactorial and includes other factors likeasthma, allergies and enlarged glandular tissues. Cuc and Cuc's investigation $^{11}$ indicates that mouth breathing has obstructive anatomic causes including tonsils or adenoid hypertrophy, nasal septum deviation and or allergic rhinitis which may occur singly or in combination.

Other factors causing nasal obstruction and thus a shift to mouth breathing are chronic allergic rhinitis, nasal traumas resulting in minor anatomic 
deformities, congenital nasal deformities, foreign bodies, polyps, and tumors ${ }^{4}$.

One study ${ }^{5}$ evaluated children presenting with mouth breathing that were compared with control non breathing children. Researchers reported that $44 \%$ of mouth breathing children presented with palatal and or pharyngeal tonsil hypertrophy and $100 \%$ of these children presented with chronic allergic rhinitis. Thus, it seems apparent that the etiology of mouth breathing is multifactorial.

\section{Clinical manifestations of mouth breathing in children}

Mouth breathing in children and adolescents is usually associated with increased lower facial height, lip apart posture, narrow alar base, narrow maxillary arch, high palatal vault, posterior cross bite and a class II dental malocclusion. This is so as the faces of mouth breathing children and adolescents develop aberrantly as a result of chronic airway obstruction $^{25}$.

One investigation ${ }^{25}$, evaluated 20 mouth breathing children with enlarged adenoids, 20 mouth breathing children with nasal obstruction and 10 nose breathing individuals (control group). Researchers reported a significant increase in IMPA, interlabial gap, and facial convexity in both mouth breathing with enlarged adenoids and in the group with mouth breathing and nasal obstruction as compared with the group of ten normal children. The upper incisor proclinationand facial convexities were higher in mouth breathing children with adenoid hypertrophy as compared with the group with nasal obstruction and with the control group.

The review of the literature ${ }^{25}$ has shown that maxillary incisors are protruded in mouth breathers and this disorder is caused by the interposition of an hypertonic lower lip between maxillary and mandibular incisors causing labioversion of maxillary incisors. One investigation ${ }^{25}$ comparing mouth breathers with controls non mouth breathers demonstrated that two different groups of mouth breathers (hypertrophied adenoids and nasal obstruction group), demonstrated a higher degree of lip separation as compared with the control group. A previous study ${ }^{9}$ demonstrated that mouth breathing patients complain of dry mouth and throat discomfort due to a reduction in the quantity and quality of saliva especially during sleep and or during awakening.Mouth breathing children usually presenta dolicofacial appearance, a narrow maxillary arch, increase in anterior facial height, and greater inclination of the mandibular plane angle ${ }^{9}$.

One study ${ }^{4}$ evaluated 67 children presenting with mouth breathing habits. All patients were referred for orthodontic examination and analysis. Researchers reported a frequency of $78 \%$ of class II skeletal relation, overjet of $4 \mathrm{~mm}$ or more, in $89.4 \%$ of mouth breathing children. Open bite or reduced overbite of less than $1 \mathrm{~mm}$ was found in $68 \%$ of mouth breathing children, posterior cross bite coexisting with class II malocclusion was observed in $65.7 \%$ of the sample and maxillary crowding was found in the $64.6 \%$. Children with abnormal craniofacial patterns show a predisposition towards some type of respiratory sleep disorder as do children with tonsillar and adenoid hypertrophy ${ }^{15}$.

Mouth breathing patients have a low oxygen concentration in their blood than those who have nasal respiration. Low oxygen concentration in the blood has been associated with high blood pressure and cardiac failures ${ }^{27}$. Mouth breathing irritates the upper airway mucosa, and children often have swollen tonsils and adenoid, one of the major causes of upper airway obstruction, sleep disorders, and sleep apnea ${ }^{27}$.

\section{Mechanism of craniofacial, dental and oral alterations in children}

Prolonged mouth breathing leads to muscular postural alterations which, in turn, cause dentoskeletal changes. One study ${ }^{25}$, points out that mouth breathing is in fact a neuromuscular disorder that secondarily causes or even increases the severity of a malocclusion. The interposition of the hypertonic lower lip between mandibular and maxillary incisors, cause labioversion of the upper incisors and linguoversion of the mandibular incisors in relation to the mandibular plane in patients with adenoid hypertrophy ${ }^{25}$. Adenoid hypertrophy is the cause of proclined mandibular incisors in mouth breathing children and this disorder is not observed in mouth breathing children without hypertrophied adenoids $^{25}$

Based on the outcome of a clinical investigation $^{7}$, researchers concluded that growth directions and craniofacial changes in form, occurs in subjects with a mouth breathing pattern due to mandibular growth rotations, increased gonial angle or increased $\mathrm{Y}$-axis and the mandibularantigonial notch may be deeper, due to mandibular flexion in the antigonial notch region by a masseter muscle imbalance.When children switch from nasal to mouth breathing, the position of the lips, tongue, and the mandible should change to provide an airway through the mouth, thus, improving breathing ability. Thus, while breathing through the mouth, all chewing motions must be stopped and/ or impeded ${ }^{9}$. Egarding one mechanism causing malocclusion, one clinical investigation ${ }^{9}$ in mouth and nasal breathing subjects, reported that mouth breathing reduces the vertical effect on the posterior teeth, which can affect the vertical position of posterior teeth negatively, leading to malocclusion.

Anterior tongue thrusting during swallowing exerts pressure forces on teeth that typically 
counteract the orthodontic forces that are applied for a closure of open bites ${ }^{17}$. It may be that enlarged adenoids aggravate and or obstruct normal nasal breathing, thus, this breathing pattern disrupts those muscle forces exerted by the tongue, cheeks and lips upon the maxillary arch and these alterations in normal oral function can lead to anomalies affecting the maxillary and mandibular arch, resulting in dental and skeletal abnormalities including malocclusion ${ }^{4}$.

One investigation ${ }^{4}$ carried out in 67 children with a mean age of 9.3 years found a correlation between nasopharyngeal airway obstruction, mouth breathing habits and the development of various skeletal and dental abnormalities. Some researchers claim that the mechanism of abnormal head posture in oral breathing children and adolescent is one in which abnormal functions such as mouth breathing, tongue thrusting, can lead to forward head posture and the development of malocclusion ${ }^{28}$.

According to one review of the literature ${ }^{15}$, facial growth abnormalities, hyperactivity, antisocial behavior, depression, cognitive difficulties and motor dysfunction are observed among mouth breathing children and the mechanism of such disorders is increased expenditure of energy during sleep. Tonsillar and adenoid hypertrophy favors the development of mouth breathing. Mouth breathing during the growth phase is responsible for triggering a chain of events resulting in growth changes and abnormalities of cranial and maxillomandibular development ${ }^{15}$.

One mechanism of dental malocclusion is mouth breathing. Mouth breathing leads to anterior facial height, a narrow and deep palate, increased lower facial height, open bite and a tendency to cross bite along with the occurrence of hearing loss ${ }^{15}$. Retruded maxilla and mandible in mouth breathing and apneic patients, leads to a smaller oral cavity, with diminished functional space for the tongue, which will occupy a more posterior position, thus favoring obstruction of the upper airway during sleep $^{15}$.

Nasal obstruction caused by tonsillar and adenoid hypertrophy impairs normal nose breathing. Patients then will have to adapt their respiration by moving over to mouth breathing through postural changes of the head, maxillae, tongue, and labial musculature, thereby altering the muscle pressure balance in the maxillae and teeth and modifying craniofacial growth and development ${ }^{15}$. Greater inclination of upper incisors in mouth breathing children and adolescents may be explained by the pressure that the tongue exerts on the palatine side of these teeth and this mechanism is caused by a retruded maxilla and mandible, which in turn, reduces the functional space for the tongue. The tongue also exerts pressure on the lower apical base, causing retroinclination of the lower incisors ${ }^{15}$.
Lymphoid tissue hypertrophy plays an important role in the pathophsyiology of both mouth breathing and sleep apneia in children and adolescents and maintaining nose breathing during childhood is important for preventing abnormalities of the facial skeleton ${ }^{15}$. Mouth breathing children extend their heads forward and downward to improve their respiratory pattern, thus increasing cervical kyphosis ${ }^{15}$. One comparative research evaluated mouth and nose breathing children and concluded that nasal airway resistance is one mechanism associated with nasal deformities and maxillary growth deficiencies.

\section{Diagnosis}

Complete visualization of adenoid tissue using endoscopic examination provides direct and tridimensional image of nasopharynx and associated adjacent structures ${ }^{25}$. Mouth breathing, low tongue posture and elongation of the lower anterior facial height are apparent at 3 years of age, but are more commonly detected after age five but the deleterious impact of decrease naso-respiratory function is virtually complete by puberty, thus the effects of mouth breathing may be diagnosed between five and twelve years of age ${ }^{25}$.

In order to correct mouth breathing in children, the pediatric dentist and or orthodontist, must be able to make a correct diagnosis to treat the dysfunction as early as possible and to prevent the onset of cascade mechanisms ${ }^{10}$. The key aspect which may be used as a guide in the diagnosis to identify a mouth breather is the "adenoid facies".

Cephalometry is useful as a screening test for anatomical abnormalities among patients with obstructive sleep apneia syndrome. The anteroposterior position of the maxilla and mandible, inclination of the mandibular and occlusal planes, position of the anterior teeth, dimensions of the nasopharyngeal and posterior air spaces are commonly associated with mouth breathing and obstructive sleep disorders and should be evaluated to obtain a proper diagnosis ${ }^{15}$.

General and pediatric dentists may be in the best position to screen and treat patients who suffer from upper airway obstruction and mouth breathing. Dentists and pediatricians often see patients on a regular basis and swollen tonsils can be easily detected by examining the back of a patient's throat $^{27}$.

\section{Treatment}

The protocol of intervention to manage mouth breathing in children include the use of a maxillary rapid expander to correct the transverse discrepancy, increase the amplitude of the upper respiratory airway and to reduce nasal resistance in 
association with the use of functional devices including a nasal and oral obturators to allow the reconstruction of a physiological balance between the perioral muscles and tongue, to obtain nasal and lips competence and to reduce overjet ${ }^{10}$.

Denotti and colleagues ${ }^{10}$ evaluated a sample of 20 patients between six and ten years of age presenting with a mouth breathing pattern. The protocol of early treatment they used included a rapid palatal expander, bonded on the deciduous molars, in association with the use of silicone myofunctional devices such as the nasal stimulator and the oral obturator that speeds and increases the effectiveness and stability of treatment to obtain a physiological balance between the perioral muscle sand the tongue, to improve overjet and to obtain lips and nose muscle competence.

Following a one-year follow up, researchers reported strengthening of the perioral musculature, lips competence and a gradual transition from oral to nasal breathing.

In experimental studies in humans ${ }^{29}$, it has been found that mouth breathing decreases considerably when patients are put on nasal CPAP, however, mouth breathing patients may still have more mouth breathing on CPAP as compared to nose breathers. Regarding treatment, there are reasons to believe that a combination of speech therapy and beclomethasone used in mouth breathing children with, asthma and allergic rhinitis may be effective.

Researchers ${ }^{24}$ reported that both modes of treatment improved respiratory pattern and functional and clinical management of asthma and allergic rhinitis in mouth breathers children and adolescents ${ }^{24}$. Surgical removal of swollen tonsils and adenoids is highly recommended when such structures negatively affect sleep by obstructing upper airway ${ }^{27}$.

\section{FINAL CONSIDERATIONS}

Based on the literature review to perform this study, it is concluded that: clinical manifestations of mouth breathing associated with craniofacial alterations in children include dental changes (greater forward inclination of upper incisors, open bite, maxillary crowding), craniofacial alterations (increased lower facial height, greater inclination of the mandibular plane), postural (lip apart posture, forward head posture, rotation and/or displacement of the mandible), musculoskeletal (class II malocclusion, open bite, class III malocclusion), anatomical (narrow alar base, narrow maxillary arch, high palatal vault, interlabial gap, hypertrophy of the lower lip, hypotrophy and hypotonicity of the upper lip, greater overjet); oclussal alterations (posterior cross bite, open bite, class II malocclusion); oral changes ( dry mouth, xerostomia, throat discomfort, low oxygen concentration, irritation of the upper airway mucosa) and neuromuscular disorders.

Mechanisms of mouth breathing causing dental and craniofacial alterations is children include obstructive anatomical mechanisms in the upper airway and nose, forward and downward head posture, mandibular rotation and flexion, hypertonic lower lip, reduction of vertical effect of muscles on the posterior teeth, anterior tongue thrusting during swallowing, disruption of muscle forces exerted by the tongue, increased expenditure of energy during sleep, smaller oral cavity, retruded maxilla and mandible and increased nasal airway resistance.

\section{REFERENCES}

1. Abreu RR, Rocha RL, Lamounier JA, Guerra AF. Etiology, clinical manifestations and concurrent features of mouth breathing children. J Pediatr (Rio J) 2008; 84: 529-35.

2. Veron HL, Antunes AG, Milanesi JD, Corrêa EC. Implications of mouth breathing on the pulmonary function and respiratory muscles. Rev CEFAC 2016; 18: 242-51.

3. Farid MM, Metwalli N. Computed Tomographic evaluation of mouth breathers among pediatric patients. Dentomaxillofac Radiol 2010; 39: 1-10.

4. Elmomani BR, Tarawneh AM, Bashdan HA, Shuqran KK. Orthodontic alterations associated with mouth breathing habit. Pakistan Oral \& Dental J 2015; 35: 234-37.

5. Lione R, Franchi L, Ghislanzone LTH, Promozic J, Buongiorno M, Cozza P. Palatal surface and volume in mouth-breathing subjects evaluated with three-dimensional analysis of digital dental casts: a controlled study. Eur J Orthod 2014; 14.

6. Moss ML. The functional matrix hypothesis revisited: The role of mechanotransduction. Am J Orthodont Dentofac Orthop 1997; 112: 410-17.

7. Ferreira FC, Corotti K, Lopes PD, Junqueira TH, Stocco JR. Association between respiratory pattern and mandibular morphology. Rev Odontol. Universidade Cidade de São Paulo 2009; 21: 18-23.

8. Fratu A. Orthodontie, diagnostic, clinical, treatment, Editora Vasiliana, Iasi, 2002.

9. Choi JE, Waddell JN, Lyons KM, Kieser JA. Intraoral $\mathrm{pH}$ and temperature during sleep with 
and without mouth breathing. J Oral Rehab 2016; 43: 356-63.

10.Denotti G, Ventura S, Arena O, Fortini A. Oral breathing: new early treatment protocol. Journal of Pediatric and Neonatal Individualized Medicine 2014; 3: 1-7.

11. Cuc A, Cuc O. Mouth breathing: An etiological factor of dental and maxillary abnormalities. Analele Universitatii Din Oradea 2013; 12: 18592.

12.Karbanda OP, Sidhu SS, Sundaran KR, Shukla DK. Oral habits in school going children of Delhi: A prevalence study. J Indian Soc Pedo Prev Dent 2003; 21; 120-24.

13.Agarwal L, Tandon R, Kulshrestha r, Gupta A. Adenoid faciais and its management: $A n$ orthodontic perspective. Indian J Orthodontics and Dentofacial Research 2016; 2: 50-5.

14.Coelho AR, Tanaka O, Ribeiro JS, Machado MA, Camargo ES. Transverse craniofacial dimensions in Angle Class II division I malocclusion according to breathing mode. Braz Oral Res2010; 24: 70-5.

15.Juliano ML, Machado MA, de Carvalho LB, do Prado L, Do Prado GF. Mouth breathing children have cephalometric patterns similar to those of adult patients with obstructive sleep apnea syndrome. Arq Neuropsiquiatr 2009; 67: 860-65.

16. Harvold EP, Vargervik K, Chierici G. Primate experiments on oral respiration. Am $\mathrm{J}$ Orthod 1981; 79: 359-73.

17.Knösel $M$, Klein S, Bleckman A, Engelke W. Coordination of tongue activity during swallowing in mouth-breathing children. Dysphagia 2012; 27: 401-407.

18.McNamara JA Jr, Brudon WL. Orthodontics and Dentofacial Orthopedics, Third Edition, Ann Arbor, Michigan: Needham Press; 2004: 123-25.

19.Pacheco MC, Casagrande CF, Teixeira LP, Finck NS, De Araújo MT. Guidelines proposal for clinical recognition of mouth breathing children. Dental Press J Orthod 2015; 20: 39-44.

20.Vig KWL. Nasal obstruction and facial growth: The strength of evidence for clinical assumptions. Am J Orthod Dentofac Orthop 1998; 113: 603-11.
21. Hitos SF, Arakaki R, Solé D, Weckx LLM. Oral breathing and speech disorders in children. $J$ Pediatr 2013; 89: 361-65.

22. Amer Acad Pediatric Dent. Policy on Oral Habits 2006; 30: 51-52.

23.Linder-Aronson S, Woodside DG, Lundstrom A. Mandibular growth direction following adenoidectomy. Am J Orthod 1986; 89: 274-84.

24.Campanha SMA, Fontes MJF, Camargos PAM, Freire LMS. The impact of speech therapy on asthma and allergic rhinitis control in mouth breathing children and adolescents. J Pediatr 2010; 86: 203-8.

25.Basheer B, Hegde KS, Bhat SS, Umar D, Baroudi K. Influence of mouth breathing on the dentofacial growth of children: Cephalometric study. JIOH 2014; 6: 50-55.

26. Nwhator SO, Ayanbadejo PO. Uncommon causes of gingivitis. J Dent Oral Hygiene 2011; 3: 65-68.

27.Jefferson $Y$. Mouth breathing: Adverse effects on facial growth, academics, and behavior. General Dent 2010; Jan/Feb: 18-25.

28.Nowak AJ, Warren JJ. Infant oral health and oral habits. Pediatr Clin North Am 2000; 47: 1043-66.

29.Bashour A, Maasilta P. Mouth breathing compromises adherence to nasal continuous positive airway pressure therapy. Chest 2004; 126: 1248-54. 